\title{
Assessment of slow rusting resistance components to stripe rust pathogen in some exotic wheat germplasm
}

\author{
VAIBHAV K. SINGH ${ }^{1 *}$, G.P. SINGH ${ }^{2}$, P.K. SINGH ${ }^{1}$, HARIKRISHNA $^{1}$, R.C. MATHURIA ${ }^{1}$, R. GOGOI ${ }^{1}$ and \\ R. AGGARWAL ${ }^{1}$ \\ ${ }^{1}$ Wheat Rust Laboratory, Division of Plant Pathology, ICAR-Indian Agricultural Research Institute, New Delhi 110012 , India \\ ${ }^{2}$ ICAR-Indian Institute of Wheat and Barley Research, Karnal 132001 , Haryana, India
}

Received: 01 December 2016/ Accepted: 22 February 2017/ Published online: 23 March 2017

C Indian Phytopathological Society 2017

\begin{abstract}
Stripe rust caused by Puccinia striiformis f. sp. tritici is one of the most destructive diseases of wheat. It is emerging as an important constraint to wheat production worldwide and northern India. Host resistance is the most economical way of controlling respective pathogen. However, race-specific resistance is overcome by the evolution of new races of the pathogens. Conversely, race non-specific or quantitative resistance, controlled by many genes and effective at the adult plat stage, is generally considered more durable and long lasting. Such type of resistance is of primary interest to wheat breeders around the world. With this background, experiments were conducted to assess the levels of slow rusting/ adult plant resistance in exotic wheat germplasm (CIMMYT Mexico Core Germplasm Panel, CIMCOG). Sixty two exotic wheat germplasm including susceptible checks were evaluated against yellow rust for resistance both at seedling as well as adult plant stages. Slow rusting/partial resistance/adult plant resistance was assessed under field conditions through host response and epidemiological parameters estimates i.e., final rust severity (FRS), coefficient of infection (Cl), relative area under disease progress curve (rAUDPC) and apparent infection rate ( $r$ ). Promising slow rusting resistance was observed on the germplasm viz., CIMCOG 1, 2, 3, 5, 6, 7, 12, 14, 15, 17, 18, 20, 21, 22, 26, 27, 28, 29, 32, 33, 34, 35, 36, 38, 40, 43, 46, 47, $49,52,53,58,59$ and 60 consistently during rabi seasons of 2013-16. All these promising stripe rust resistant germplasm at adult plant stage were susceptible at seedling stage to yellow rust, which indicated presence of slow rusting resistance among the germplasm. Significant diversity was observed for level of slow rusting resistance among the CIMMYT core wheat germplasm, which may be exploited in further breeding strategies to develop consistent and durable resistant varieties against stripe rust in India.
\end{abstract}

Keywords: Adult plant resistance, Puccinia striiformis f. sp. tritici, seedling resistance, slow rusting, stripe rust, wheat

Wheat rusts have been the most important biotic stresses responsible for unstable production in wheat globally. Among the three rusts of wheat (stripe, leaf and stem), significantly high yield reduction is brought by stripe (or yellow) rust caused by Puccinia striiformis Westend. f. sp. tritici Eriks. \& Henn. (Chen et al., 2014). Yellow rust remains a major constraint in Asia, threatening 43 million ha of wheat area. In India, yellow rust has gained importance in recent past particularly in North Western Plain Zone as well as Northern Hills Zone due to favourable weather conditions (low temperature and high humidity) and poses a potential threat to wheat crop of these areas (Saharan et al., 2010). In the year 2014-15, this disease appeared on most of the popular wheat cultivars planted in plains of Jammu \& Kashmir, foot hills of Himachal Pradesh, different parts of Haryana, Punjab, Uttarakhand and bordering fields in Uttar Pradesh (Saharan et al., 2015).

Although several effective fungicides are available for control of yellow rust, its use increases production cost and not considered environment friendly (Singh et

*Corresponding author: dr.singhvaibhav @ gmail.com al., 2005). Growing cultivars with adequate level of genetic resistance remains the most efficient and environmentally safe means of controlling stripe rust. It is achieved by deployment of cultivars with race-specific/ or race-nonspecific resistance. Race-specific resistance genes provide highly effective protection against the pathogenic races depending on a specific recognition event between the host and the pathogen in accordance with gene-for-gene interaction but are not considered durable (Boyd, 2005). Conversely, race-nonspecific resistance in wheat, also referred as slow rusting, adult plant resistance or partial resistance, is mainly polygenic, long-lasting and more durable (Herrera-Foessel et al., 2011). Characteristics of race non-specific resistance in the wheat-Puccinia system include a non-hypersensitive and (or) partial resistance response with variable disease severity levels under field conditions across locations and years. A more durable resistance to rusts involves slow rusting, a form of partial resistance in which host genotypes retard or delay rust development by various means. Cultivars possessing slow rusting resistance display high infection type at seedling growth stage and is quantitatively inherited (Navabi et al., 2004). In many 
cereal-rust patho-systems, the quantitative aspects of host resistance have been investigated by disease severity at a certain crop development stage, the area under the disease progress curve (AUDPC) or by apparent infection rate $(r)$ and coefficient of infection $(\mathrm{Cl})$ values for slow rusting/adult plant resistance (Pathan and Park, 2006; Shah et al., 2014; Singh et al., 2015). Keeping in view of these facts, the present study was designed to assess the levels of slow rusting/partial resistance/adult plant resistance against yellow rust pathogen in some exotic wheat germplasm and the results are discussed.

\section{MATERIALS AND METHODS}

\section{Plant material}

The seed of sixty two exotic wheat germplasm (CIMMYT Mexico Core Germplasm Panel, CIMCOG) including two highly susceptible checks (A-9-30-1 and Kathia red) were obtained from the Division of Genetics, ICAR-Indian Agricultural Research Institute, New Delhi. All these germplasm were evaluated for resistance at both the seedling and adult plant stages to mix pathotypes of yellow rust during three consecutive rabi seasons of 2013-14, 2014-15 and 2015-16 at ICAR-Indian Agricultural Research Institute, New Delhi, India (Latitude $28^{\circ} 38^{\prime 2} 23^{\prime \prime} \mathrm{N}$; Longitude $77^{\circ} 09^{\prime} 27^{\prime \prime} \mathrm{E}$; MSL 228.61m).

\section{Rust pathotypes}

The urediospores inoculum of stripe rust was received as mixtures of most common races namely, I(38S102), $\mathrm{K}(47 \mathrm{~S} 102), \mathrm{L}(70 S 69), \mathrm{P}(46 \mathrm{~S} 102), 46 S 119$ and $78 S 84$ from the ICAR-Indian Institute of Wheat and Barley Research, Regional Station, Flowerdale, Shimla. The urediospores inoculums were multiplied in polyhouse on stripe rust susceptible cv. Kathia red following standard procedures (Joshi et al., 1988).

\section{Seedling reaction test}

The seedlings of sixty two exotic wheat germplasm including two susceptible checks were raised in aluminum trays (11 $\times 4 \times 3$ inch) in uniformly fertilized soil. Ten days old seedlings were used for inoculation with urediospore suspension of the mix pathotypes prepared by mixing spore dust with a few drops of water and a pinch of Tween-20 to break the surface tension. Adequate water was added to make the suspension of spore and filled in a glass atomizer and sprayed uniformly on the seedlings. Inoculated seedlings were sprayed with a thin mist of water and kept in moist chambers for $48 \mathrm{~h}$ for incubation maintained with $16-18^{\circ} \mathrm{C}, 100 \%$ relative humidity and $12 \mathrm{~h}$ daylight. The seedlings were then transferred to greenhouse benches and kept at $16 \pm 2^{\circ} \mathrm{C}$ temp in $80-90 \%$ relative humidity of, and illuminated at about 15,000 lux for $12 \mathrm{~h}$. Infection types (ITs) on the test lines were recorded 14 days after inoculation according to scale based on Stakman et al. (1962), with suitable modifications (Bhardwaj et al., 2010).

\section{Assessment of slow rusting/adult plant resistance in field}

The same sets of 62 exotic wheat germplasm including two susceptible checks were sown in Randomized Block Design (RBD) with three replications. Each germplasm was sown in two rows of one meter plot length spaced at $25 \mathrm{~cm}$ apart. The irrigation channels were made on the space given between two replicates. The experimental material was surrounded by two rows of the mixture of highly susceptible cvs. A-9-30-1 and Kathia red to provide high and uniform disease pressure in field. Inoculation to infector rows was carried out with urediospores suspension prepared by mixing spore dust in water with the help of Tween-20 and sprayed on infector rows through hand sprayer during evening time.

Slow rusting resistance was assessed through host response and epidemiological parameters estimates i.e., final rust severity (FRS), area under rust progress curve (AURPC), relative area under rust progress curve (rAURPC), coefficient of infection $(\mathrm{Cl})$ and apparent infection rate $(r)$. Yellow rust severity (per cent) was recorded six times at weekly intervals, starting when susceptible checks reached 30 per cent severity from individual plots in all the replications according to the modified Cobb's scale (Peterson et al., 1948), and adult plant infection types were categorized as resistant $(R)$, moderately resistant (MR), moderately susceptible (MS) and susceptible (S) reactions based on Roelfs et al. (1992). Coefficient of infection which is calculated by multiplying disease severity and constant values of infection type, was used for estimating AURPC and apparent infection rate $(r)$. The constant values for infection types were used based on, Immune $=0, R=$ $0.2, \mathrm{MR}=0.4, \mathrm{M}=0.6, \mathrm{MS}=0.8, \mathrm{~S}=1$ (Stubbs et al., 1986). The AURPC and rAURPC were calculated for the germplasms using the formula given by Milus and Line (1986). Also, the apparent infection rate ( $r$ ) was estimated in terms of disease severity recorded on germplasms at different times (Van der Plank, 1968). The analysis of variance was done to determine the significance of the differences among the germplasms for adult plant resistance parameters. Computer program SPSS version 16.0 was used for analysis of variance and correlation coefficient.

\section{RESULTS AND DISCUSSION}

\section{Seedling resistance test}

The detailed results presented in Table 2 demonstrate the status of seedling resistance of all 62 exotic wheat germplasm including two susceptible checks. Out of these, eight germplasm viz., CIMCOG 6, 14, 20, 21, 33, 40,47 and 53 expressed resistant reaction, 22 germplasm viz., CIMCOG 2, 5, 7, 15, 17, 18, 22, 27, 28, $29,32,34,35,36,38,39,46,49,50,52,59$ and 60 showed moderately susceptible reaction, and 22 lines namely CIMCOG 1, 3, 8, 9, 10, 11, 12, 13, 19, 23, 24, $26,31,37,42,43,44,45,54,55,56,58$ were susceptible. Result of the study showed that, almost all the tested 
Table 1. Analysis of variance for slow rusting resistance parameters (FRS, Cl, rAURPC and $r$ ) among 62 exotic wheat germplasm including susceptible checks for stripe rust

\begin{tabular}{lccccc}
\hline Source of variation & D.f. & \multicolumn{4}{c}{ Mean square value for slow rusting resistance parameters* } \\
\cline { 3 - 5 } & & FRS & Cl & rAURPC & $r$ \\
\hline Cultivars & 61 & $2401.55^{* *}$ & $2570.58^{* *}$ & $2415.18^{* *}$ & $0.34^{* *}$ \\
Replications & 2 & 219.82 & 112.82 & 149.83 & 0.23 \\
Cultivars x Replications & 122 & 20.53 & 15.15 & 3.78 & 0.64 \\
Total error & 185 & 802.77 & 852.45 & 794.93 & 0.12 \\
\hline
\end{tabular}

${ }^{\star} \mathrm{FRS}=$ Final rust severity, $\mathrm{Cl}=$ Coefficient of infection, $\mathrm{rAURPC}=$ relative Area under rust progress curve, $r=$ Apparent infection rate; D.f. $=$ degree of freedom; ${ }^{* *}$ indicate significant difference at $\mathrm{P}<0.01$ and $\mathrm{P}<0.05$

genotypes were susceptible at seedling stage to stripe rust, were subjected to study their effectiveness for slow rusting/adult plant resistance under field conditions.

\section{Slow rusting/adult plant resistance under field conditions}

Slow rust resistance in exotic wheat germplasms were assessed based on the host response. Different epidemiological parameters (FRS, Cl, rAURPC and $r$ ) prevailed under field conditions were taken into consideration. The analysis of variance revealed that there was highly significant $(p<0.01)$ difference among exotic wheat germplasms for all the parameters studied (Table 1). Results with individual parameters are described as under:

Final rust severity (FRS): A considerably high disease pressure was observed as revealed from severity on susceptible checks (100\% FRS). Twelve genotypes having 'TR' infection type, 20 genotypes having 'MR' infection type, while 8 genotypes having 'MS' infection type were observed (Table 2). The cultivars which had MS or MR infection type may carry durable resistance genes (Singh et al., 2005). Similarly, based on FRS, the tested genotypes were grouped into three ranges i.e., high, moderate and low level of partial resistance having $1-20 \%, 21-40 \%$ and $41-60 \%$ FRS, respectively. The genotypes CIMCOG 1, 2, 3, 5, 6, 7, 12, 14, 15, 17, 18, $20,21,22,26,27,28,29,32,33,34,35,36,38,40,43$, $46,47,49,52,53,58,59$ and 60 were included in first group. CIMCOG 10, 13, 19, 23, 31, 39, 50 and 56 were marked as moderate level, while CIMCOG 9, 11, 42, 44, 45 and 54 were designated as having low level of partial resistance. This FRS is assumed to represent the cumulative result of all resistance factors during the progress of epidemic (Parlevliet, 1979). Many researchers used FRS as a parameter to assess slow rusting behaviour of wheat lines (Herrera-Foessel et al., 2007; Shah et al., 2014; Subodh et al., 2014). They observed low value for wheat lines exhibiting slow rusting, as compared to susceptible germplasm. Similarly, Singh et al. (2015) also conducted field assessment of slow rusting to yellow rust for ranking wheat cultivars and as per the resistance level based on FRS along with other slow rusting parameters, they found that resistance level ranged from very low to very high among the tested lines.
Cl value: The data on disease severity and host reaction was combined to calculate coefficient of infection. Genotypes with $\mathrm{Cl}$ values of 0-20, 21-40 and 41-60 were regarded as possessing high, moderate and low levels of APR, respectively. Genotypes CIMCOG 1, 2, 3, 5, 6, $7,12,14,15,20,21,22,26,27,28,29,32,33,34,35$, $36,38,39,40,43,46,47,49,50,52,53,58,59$ and 60 having $\mathrm{Cl}$ value up to 20 were marked in first group. CIMCOG 10, 13, 19, 23, 31 and 56 exhibited $\mathrm{Cl}$ value up to 40 were marked as moderately resistant, while CIMCOG 9, 11, 24, 42, 44, 45 and 54 showed CI value up to 60 were marked as having low level of adult plant resistance. Previously, Pathan and Park (2006) appraised adult plant resistance, a kind of slow rusting resistance, to leaf rust in European wheat lines by calculating $\mathrm{Cl}$ value and reported the presence of different partial resistance conferring genes in these lines. Similarly, many researchers reported the presence of varying levels of slow rusting in wheat breeding lines (Shah et al., 2014; Singh et al., 2015).

r AURPC value: The test genotypes were categorized into two distinct groups for partial resistance, based on their rAURPC values. One group included the genotypes exhibiting rAUDPC values up to $30 \%$ of the check, and the other included the cultivars showing rAUDPC values up to $60 \%$ of the check. In these cultivars, rust pustules appear with sporulation but with final chlorotic and necrotic strips (MR and/or MS infection types) were observed. Subsequently, the prog-ress of rust development remained slower and restricted. The cultivars in group 1 were marked as having better slow rusting and that of group 2 were marked as having moderately slow rusting. The reasons for the markings were because they also developed epiphytotic of very low potential as indicated by their rAUDPC values, despite the ultimate expression of high infection type. Cultivars with such traits are expected to possess genes that con-fer partial resistance (Parlevliet, 1988). Apart from six cultivars having resistance 'TR' infection type at adult plant stage, the remaining genotypes that exhibited rAURPC value less than $30 \%$ of susceptible checks were considered as having better level of partial resistance (Table 2). This group was composed of cultivars with varying degrees of adult plant resistance, which has been advocated to be more durable (Singh et al., 2004; Safavi et al., 2013). Moreover, cultivars with acceptable levels of slow rusting restrict the evolution of new virulent races 
Table 2. Seedling and adult plant reaction, mean values of final rust severity (FRS), coefficient of infection (CI), rAURPC and infection rate $(r)$ in exotic wheat germplasm to stripe rust during rabi seasons of 2013-16*

\begin{tabular}{|c|c|c|c|c|c|c|}
\hline \multirow[t]{2}{*}{ Germplasm } & \multirow{2}{*}{$\begin{array}{l}\text { Seedling } \\
\text { reaction }\end{array}$} & \multicolumn{5}{|c|}{ Mean value of slow rusting resistance parameters ${ }^{\mathrm{b}}$} \\
\hline & & Adult plant reaction $^{\mathrm{b}}$ & FRS & $\mathrm{Cl}$ & rAURPC & $r$ \\
\hline CIMCOG 1 & S & MS & 10 & 8 & 5.58 & 0.03 \\
\hline CIMCOG 2 & MS & MR & 10 & 4 & 2.79 & 0.01 \\
\hline CIMCOG 3 & $S$ & MS & 20 & 16 & 12.95 & 0.09 \\
\hline CIMCOG 4 & 0 & 0 & 0 & 0 & 0 & 0 \\
\hline CIMCOG 5 & MS & MR & 10 & 4 & 2.66 & 0.01 \\
\hline CIMCOG 6 & $\mathrm{R}$ & TR & 1 & 0.2 & 0.15 & 0 \\
\hline CIMCOG 7 & MS & MR & 5 & 2 & 1.2 & 0.01 \\
\hline CIMCOG 8 & $S$ & $S$ & 80 & 80 & 73.8 & 0.27 \\
\hline CIMCOG 9 & $S$ & $S$ & 60 & 60 & 54.76 & 0.22 \\
\hline CIMCOG 10 & $S$ & MS & 40 & 32 & 21.71 & 0.09 \\
\hline CIMCOG 11 & $S$ & $S$ & 60 & 60 & 53.17 & 0.22 \\
\hline CIMCOG 12 & $S$ & MS & 20 & 16 & 15.23 & 0.09 \\
\hline CIMCOG 13 & $S$ & MS & 40 & 32 & 29.33 & 0.07 \\
\hline CIMCOG 14 & $\mathrm{R}$ & TR & 1 & 0.2 & 0.15 & 0 \\
\hline CIMCOG 15 & MS & TR & 1 & 0.2 & 0.15 & 0 \\
\hline CIMCOG 16 & 0 & 0 & 0 & 0 & 0 & 0 \\
\hline CIMCOG 17 & MS & MR & 5 & 2 & 1.2 & 0.01 \\
\hline CIMCOG 18 & MS & TR & 1 & 0.2 & 0.15 & 0 \\
\hline CIMCOG 19 & $S$ & $S$ & 40 & 40 & 28.73 & 0.19 \\
\hline CIMCOG 20 & $\mathrm{R}$ & TR & 1 & 0.2 & 0.15 & 0 \\
\hline CIMCOG 21 & MR & MR & 5 & 2 & 1.2 & 0.01 \\
\hline CIMCOG 22 & MS & MR & 10 & 4 & 2.79 & 0.01 \\
\hline CIMCOG 23 & $S$ & $S$ & 30 & 30 & 20.79 & 0.14 \\
\hline CIMCOG 24 & $S$ & $S$ & 50 & 50 & 40.47 & 0.19 \\
\hline CIMCOG 25 & 0 & 0 & 0 & 0 & 0 & 0 \\
\hline CIMCOG 26 & $S$ & TR & 1 & 0.2 & 0.15 & 0 \\
\hline CIMCOG 27 & MS & MR & 10 & 4 & 2.79 & 0.01 \\
\hline CIMCOG 28 & MS & MR & 20 & 8 & 7.11 & 0.04 \\
\hline CIMCOG 29 & MS & MR & 10 & 4 & 2.79 & 0.01 \\
\hline CIMCOG 30 & 0 & 0 & 0 & 0 & 0 & 0 \\
\hline CIMCOG 31 & $S$ & MS & 40 & 32 & 29.33 & 0.09 \\
\hline CIMCOG 32 & MS & MR & 20 & 8 & 6.47 & 0.04 \\
\hline CIMCOG 33 & MR & MR & 5 & 2 & 1.2 & 0.01 \\
\hline CIMCOG 34 & MS & MR & 20 & 8 & 5.84 & 0.04 \\
\hline CIMCOG 35 & MS & MR & 20 & 8 & 3.3 & 0.05 \\
\hline CIMCOG 36 & MS & MR & 20 & 8 & 6.47 & 0.04 \\
\hline CIMCOG 37 & $S$ & $S$ & 80 & 80 & 72.22 & 0.27 \\
\hline CIMCOG 38 & MS & TR & 1 & 0.2 & 0.15 & 0 \\
\hline CIMCOG 39 & MS & MR & 40 & 16 & 14.03 & 0.05 \\
\hline CIMCOG 40 & $\mathrm{R}$ & TR & 1 & 0.2 & 0.15 & 0 \\
\hline CIMCOG 41 & 0 & 0 & 0 & 0 & 0 & 0 \\
\hline CIMCOG 42 & $S$ & $S$ & 60 & 60 & 53.17 & 0.21 \\
\hline CIMCOG 43 & $S$ & MS & 20 & 16 & 15.23 & 0.09 \\
\hline CIMCOG 44 & $S$ & $S$ & 50 & 50 & 38.25 & 0.19 \\
\hline CIMCOG 45 & $S$ & $S$ & 60 & 60 & 51.58 & 0.21 \\
\hline CIMCOG 46 & MS & TR & 1 & 0.2 & 0.09 & 0 \\
\hline CIMCOG 47 & $\mathrm{R}$ & TR & 1 & 0.2 & 0.09 & 0 \\
\hline CIMCOG 48 & 0 & 0 & 0 & 0 & 0 & 0 \\
\hline CIMCOG 49 & MS & TR & 1 & 0.2 & 0.22 & 0 \\
\hline CIMCOG 50 & MS & MR & 40 & 16 & 14.03 & 0.05 \\
\hline CIMCOG 51 & 0 & 0 & 0 & 0 & 0 & 0 \\
\hline CIMCOG 52 & MS & TR & 1 & 0.2 & 0.15 & 0 \\
\hline CIMCOG 53 & MR & MR & 5 & 2 & 1.2 & 0.01 \\
\hline CIMCOG 54 & $S$ & $S$ & 60 & 60 & 48.41 & 0.21 \\
\hline CIMCOG 55 & $S$ & $S$ & 80 & 80 & 72.22 & 0.27 \\
\hline CIMCOG 56 & $S$ & MS & 40 & 32 & 28.06 & 0.08 \\
\hline CIMCOG 57 & 0 & 0 & 0 & 0 & 0 & $\begin{array}{c}0 \\
\text { Contd... }\end{array}$ \\
\hline
\end{tabular}




\begin{tabular}{lcccccc}
\hline CIMCOG 58 & S & MR & 5 & 2 & 1.07 & 0.01 \\
CIMCOG 59 & MS & MR & 20 & 8 & 6.47 & 0.04 \\
CIMCOG 60 & MS & MR & 10 & 4 & 2.66 & 0.01 \\
Susceptible check & & & & & & 100 \\
A-9-30-1 & $\mathrm{S}$ & $\mathrm{S}$ & 100 & 100 & 0.37 \\
Kathia red & $\mathrm{S}$ & $\mathrm{S}$ & 100 & $6.34+2.24$ & $3.16+1.21$ & $0.41+0.14$ \\
\hline LSD (5\%) & & & $7.38+2.61$ & 100 & 0.37 \\
\hline
\end{tabular}

*Pooled data of three consecutive rabi seasons of 2013-14, 2014-15 and 2015-16; aSeedling infection types (ITs) based on Stakman, with modifications (Bhardwaj et al., 2010); 'd Adult plant infection types based on Roelfs et al. (1992) as TR=Trace Responses; R=Resistant, presence of hypersensitive necrotic or chlorotic flecks but no uredinia; MR=Moderately Resistant, small pustules surrounded by necrotic areas; MS=Moderately Susceptible, medium sized pustules, no visible necrosis but there is chlorosis; $\mathrm{S}=$ Susceptible, large pustules, no necrosis or chlorosis; bData based on weekly disease observations.

of the pathogen because multiple point mutations are extremely rare in nature (Ali et al., 2007).

Apparent infection rate (r) value: Apparent infection rate $(r)$ of all germplasm was less than the susceptible checks ( $r$-value 0.37). Genotypes CIMCOG 6, 14, 15, $18,20,26,38,40,46,47$ and 49 showed a constant disease severity having 'TR' infection type, thus showing no increase per unit time with $r$-value of 0 . Apart from susceptible checks, the highest $r$-value $(0.21-0.27)$ was recorded for CIMCOG 8, 9, 11, 37, 42, 45, 54 and 55 followed by CIMCOG 19, 23, 24 and 44 ( $r$-value $=0.14-$ 0.19 ) belonging to sus-ceptible (S) and moderately susceptible (MS) group, respectively based on FRS, CI, and rAURPC values. In this study, cultivars marked as having high level of slow rusting indicated an infection rate less than 0.05 , while cultivars having moderate level of slow rusting had an infection rate ranging from 0.06 to 0.09 with regard to other slow rusting parameters (Table 2).

Association between slow rusting resistance parameters: Efforts were made to elucidate the association between field-based slow rusting resistance parameters across 62 exotic wheat germplasms including susceptible checks for stripe rust. Coefficient of infection is the mostly used parameter for the purpose (Ali et al., 2009). A positive relation of coefficient of infection was observed with FRS, rAURPC and infection rate $(r)$ with a strong $\mathrm{R}^{2}$ value that was $0.98,0.97$ and 0.95 , respectively (Fig. $1 \mathrm{a}, \mathrm{b}$ and $\mathrm{c}$ ). This positive correlation is in agreement with the results of other researchers on cereals-rust pathosystems (SandovalIslas et al., 2007; Safavi et al., 2013; Singh et al., 2015). Sandoval-Islas et al. (2007) found good correlation of rAUDPC with quantitative resistance components i.e., latent period and infection frequency. Field selection of the slow rusting trait preferably by low rAURPC and FRS along with $\mathrm{Cl}$, is feasible where greenhouse facilities are inadequate (Singh et al., 2007). Ochoa and Parlevliet (2007) also found a high correlation coefficient between rAUDPC and yield losses. Since all these parameters were strongly and positively correlated in the present study, it can be concluded that FRS and $\mathrm{Cl}$ are the most appropriate parameters.

The overall results demonstrate that the CIMMYT core wheat germplasm (CIMCOG) have significant
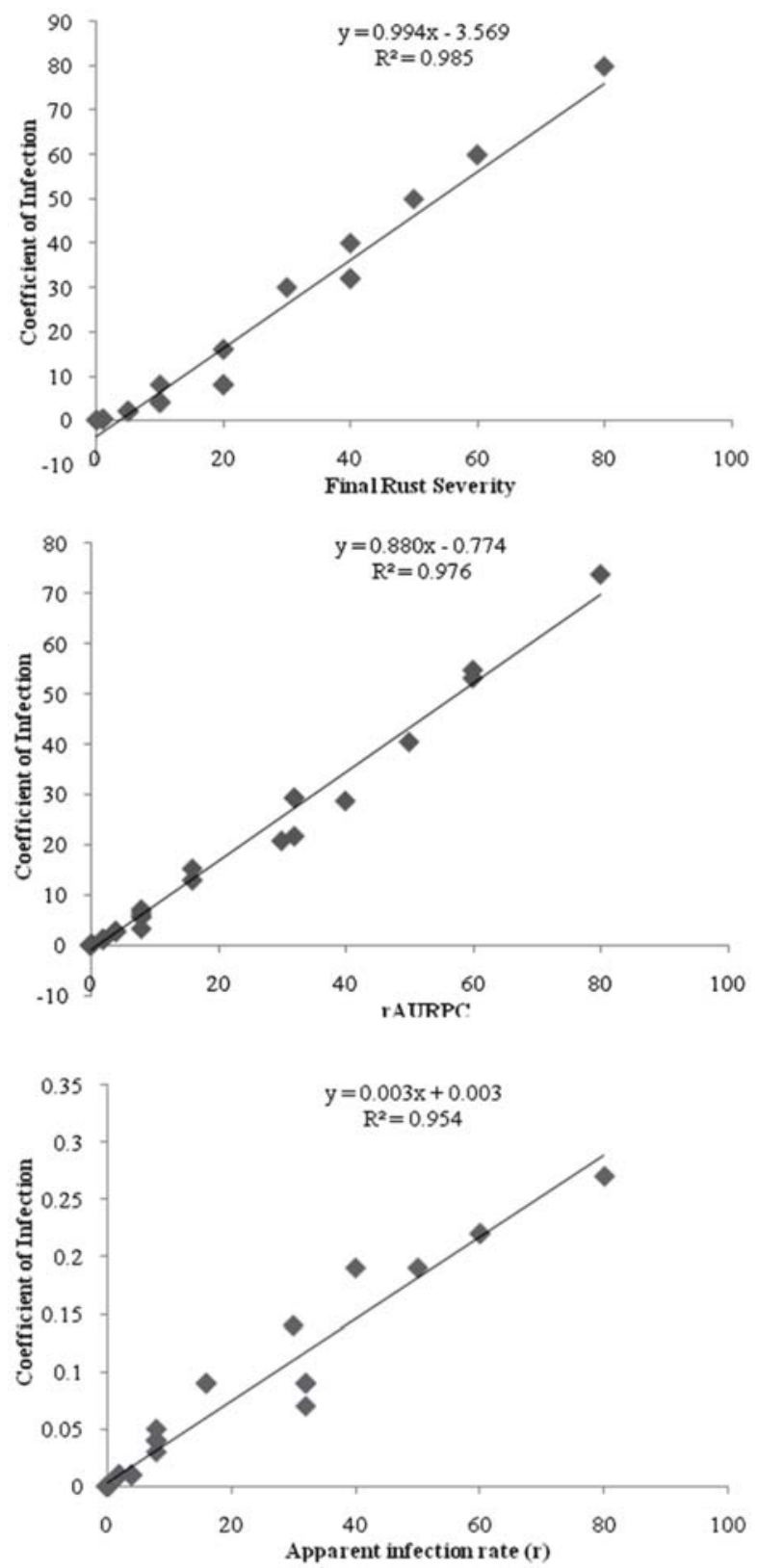

Fig. 1. (a) Association between final rust severity (FRS) and coefficient of infection for assessment of slow rusting resistance, (b) Association between rAURPC and coefficient of infection for assessment of slow rusting resistance and (c) Association between apparent infection rate $(r)$ and coefficient of infection for assessment of slow rusting resistance 
diversity regarding resistance reaction, ranging from moderate resistance to susceptible ones. Most of the evaluated germplasm exhibited moderate or good performance under high yellow rust incidence which was confirmed from a comparative susceptible check. Resistance was observed in all categories of slow rusting resistance to stripe rust pathogen, which may be used in wheat improvement program with suitable breeding strategies. Furthermore, confirmatory studies are required to develop more durable varieties as a management strategy against stripe rust.

\section{ACKNOWLEDGMENTS}

Authors are thankful to the ICAR-Indian Institute of Wheat \& Barley Research, Regional Station, Flowerdale, Shimla for providing stripe rust inoculum, and the Division of Genetics, ICAR-Indian Agricultural Research Institute, New Delhi for providing wheat seed material. The valuable guidance and support from the Head, Division of Plant Pathology, ICAR-IARI, New Delhi is highly acknowledged.

\section{REFERENCES}

Ali S, Shah SJA and Ibrahim M (2007). Assessment of wheat breeding lines for slow yellow rusting. Pak. J. Bio. Sci. 10: 3440-3444.

Ali S, Shah SJA, Khalil IH, Rahman H, Maqbool K and Ullah W (2009). Partial resistance to yellow rust in winter wheat germplasm at north Pakistan. Aust. J. Crop Sci. 3: 37-43.

Bhardwaj SC, Prashar M, Jain SK, Kumar S and Datta D (2010). Adult plant resistance in some Indian wheat genotypes and postulation of leaf rust resistance genes. Indian Phytopath. 63: 174-180.

Boyd LA (2005). Centenary review: Can Robigus defeat an old enemy? yellow rust. J. Agric. Sci. 143: 1-11.

Chen W, Wellings C, Chen X and Liu T (2014). Wheat stripe rust caused by Puccinia striiformis tritici. Mol. Plant Pathol. 15: 433-446.

Herreraa-Foessel SA, Singh RP, Huerta-Espino J, Crossa J, Djurle A and Yuen J (2007). Evaluation of slow rusting resistance to leaf rust in CIMMYT durum wheats. Euphytica 155: 361-369.

Herrera-Foessel SA, Lagudah ES, Huerta-Espino J, Hayden MJ, Bariana HS, Singh D and Singh RP (2011). New slow rusting leaf rust and stripe rust resistance genes $L$ r67 and Yr46 in wheat are pleiotropic or closely linked. Theor. Appl. Gen. 122: 239-249.

Joshi LM, Singh DV and Srivastava KD (1988). Technique in wheat disease. In: Manual of wheat, Malhotra Publishing House, New Delhi. pp. 15-75.

Milus EA and Line RF (1986). Gene action for inheritance of durable, high-temperature, adult plant resistances to stripe rust in wheat. Phytopathology 76: 435-441.

Navabi A, Singh RP, Tewari JP and Briggs KG (2004). Inheritance of high levels of adult-plant resistance to stripe rust in five spring wheat genotypes. Crop Sci. 44: 11561162.

Ochoa J and Parlevliet JE (2007). Effect of partial resistance to barley leaf rust, Puccinia hordei, on the yield of three barley cultivars. Euphytica 153: 309-312.

Parlevliet JE (1979). Components of resistance that reduce the rate of epidemic development. Annu. Rev. Phytopathol. 17: 203-222.
Parlevliet JE (1988). Strategies for utilization of partial resistance for control of rust. In: Breeding strategies for resistance to wheat rusts. Simmonds NW and Rajaram S (Eds.). CIMMYT, Mexico, pp. 151.

Pathan AK and Park RF (2006). Evaluation of seedling and adult plant resistance to leaf rust in European wheat cultivars. Euphytica 149: 327-342.

Peterson RF, Campbell AB and Hannah AE (1948). A diagrammatic scale for estimating rust intensity on leaves and stem of cereals. Can. J. Res. Sec. 26: 496-500.

Roelfs AP, Singh RP and Saari EE (1992). Rust diseases of wheat: concept and methods of diseases management. CIMMYT, Mexico. pp. 81

Safavi SA, Ahari AB, Afshari F and Arzanlou M (2013). Slow rusting resistance in Iranian barley cultivars to Puccinia striiformishordei. J. Plant Prot. Res. 53: 2-7.

Saharan MS, Kumar S, Selvakumar R and Sharma I (2015). Wheat crop health report of Feb-March 2015.Directorate of Wheat Research, Karnal. Wheat Crop Health Newsletter 20: 1-7.

Saharan MS, Sharma AK, Singh SS and Singh M (2010). Stripe rust resistance status in Indian popular cultivars of wheat. In: Borlaug Global Rust Initiative 2010 Technical Workshop. St. Petersburg, Russia, 1-4 June, 2010, Poster abstract. pp. 31.

Sandoval-Islas JS, Broers LHM, Mora-Aguilera G, Parlevliet JE, Osada KS and Vihar HE (2007). Quantitative resistance and its components in barley to yellow rust. Euphytica 153: 295-308.

Shah SJA, Hussain S, Ahmad M, Farhatullah and Ibrahim M (2014). Characterization of slow rusting resistance against Puccinia striiformis f.sp.tritici in candidate and released bread wheat cultivars of Pakistan. J. Plant Pathol. Microbiol. 5: 1-9.

Singh D, Park RF and Mclntosh RA (2007). Characterization of wheat leaf rustresistance gene Lr34 in Australian wheats using components of resistance and the linked molecular marker csLV34. Aust. J. Agric. Res. 58: 1106-1114.

Singh RP, Huerta-Espino J and William HM (2005). Genetics and breeding for durable resistance to leaf and stripe rusts in wheat. Turkish J. Agric. Forestry 29: 121-127.

Singh RP, William HM, Huerta-Espino J and Rosewarne G (2004). Wheat Rust in Asia: Meeting the challenges with old and new technologies. In: New directions for a diverse planet. Proceedings of the $4^{\text {th }}$ International Crop Science Congress, Brisbane, Australia.

Singh RP, William HM, Huerta-Espino $\mathrm{J}$ and Rosewarne $\mathrm{G}$ (2005). Wheat rust in Asia: meeting the challenges with old and new technologies. In: Proceedings of the 4th international crop science congress, Brisbane, Australia, 26 Sep-1 Oct 2004.

Singh VK, Mathuria RC, Singh GP, Singh PK, Singh S, Gogoi R and Aggarwal R (2015). Characterization of yellow rust resistance genes by using gene postulation and assessment of adult plant resistance in some Indian wheat genotypes. Res. Crops 16: 741-750.

Stakman EC, Stewart DM and Loegering WQ (1962). Identification of physiologic races of Puccinia graminis tritici. U S Agriculture Research Service. 17: 1-53.

Stubs RW, Prescot JM, Saari EE and Dubi HJ (1986). Cereal disease methodology manual. CIMMYT, Mexico, pp. 46.

Subodh K, Awasthi RP and Kumar J (2014). Adult plant resistance in some Indian wheat cultivars and postulation of yellow rust resistance genes. Indian Phytopath. 67: 134137.

Van der Plank JE (1968). Disease Resistance in Plants. New York, Academic Press, pp. 206. 